\title{
Novel Insights into Lithium's Mechanism of Action: Neurotrophic and Neuroprotective Effects
}

\author{
Jorge A. Quiroz ${ }^{\mathrm{a}}$ Rodrigo Machado-Vieira ${ }^{\mathrm{b}}$ Carlos A. Zarate, Jr. ${ }^{\mathrm{b}}$ \\ Husseini K. Manjic \\ ${ }^{a}$ Hoffman-La Roche Inc., Pharma Development and Exploratory Neuroscience, Nutley, N.J., \\ ${ }^{b}$ Experimental Therapeutics, Mood and Anxiety Disorders Research Program, NIMH-NIH, Bethesda, Md., and \\ 'Johnson \& Johnson Pharmaceutical Research and Development, L.L.C., Titusville, N.J., USA
}

\section{Key Words}

Neurodegenerative disorders $\cdot$ B-cell lymphoma $2 \cdot$ Protein kinase $C \cdot$ Glycogen synthase kinase $3 \cdot$ Brain-derived neurotrophic factor $\cdot$ Arachidonic acid $\cdot$ Bipolar disorder

\begin{abstract}
The monovalent cation lithium partially exerts its effects by activating neurotrophic and neuroprotective cellular cascades. Here, we discuss the effects of lithium on oxidative stress, programmed cell death (apoptosis), inflammation, glial dysfunction, neurotrophic factor functioning, excitotoxicity, and mitochondrial stability. In particular, we review evidence demonstrating the action of lithium on cyclic adenosine monophosphate (cAMP)-mediated signal transduction, CAMP response element binding activation, increased expression of brain-derived neurotrophic factor, the phosphatidylinositide cascade, protein kinase $C$ inhibition, glycogen synthase kinase 3 inhibition, and B-cell lymphoma 2 expression. Notably, we also review data from clinical studies demonstrating neurotrophic effects of lithium. We expect that a better understanding of the clinically relevant pathophysiological targets of lithium will lead to improved treatments for those who suffer from mood as well as neurodegenerative disorders.

Copyright $\odot 2010$ S. Karger AG, Basel
\end{abstract}

Over the past several years, significant evidence has expanded our understanding of how lithium might exert its mood-stabilizing properties in individuals suffering from bipolar disorder. As a result of novel insights into these mechanisms, recent work has demonstrated that this monovalent cation induces its cellular and molecular effects, at least partially, by activating neurotrophic and neuroprotective pathways and its associated signaling mechanisms. Although the changes that lithium exerts to produce mood-stabilizing effects have not been completely clarified, a growing body of evidence supports that neurotrophic cascades might be the common denominator underlying lithium's therapeutic efficacy. In this review, we evaluate each of the currently identified mechanisms of action, as well as the comparatively limited evidence available from human studies demonstrating the neurotrophic and neuroprotective effects of lithium.

\section{Neurotrophic Signaling Cascades}

Neurotrophins (NTs) are a family of regulatory factors. They are known to mediate the differentiation and survival of neurons, as well as the modulation of synaptic

\section{KARGER}

(c) 2010 S. Karger AG, Basel

Fax +41613061234

E-Mail karger@karger.ch

www.karger.com www.karger.com/nps
Husseini K. Manji, MD, FRCPC

Johnson \& Johnson Pharmaceuticals Group

1125 Trenton-Harbourton Road, E32000

Titusville, NJ 08560 (USA)

Tel. +1 609730 2968, Fax +1 609730 2940, E-Mail hmanji@its.jnj.com 
transmission and synaptic plasticity. Members of the NT family include nerve growth factor (NGF), brain-derived neurotrophic factor (BDNF), NT-3, NT-4, NT-5, and NT6. BDNF and other neurotrophic factors are necessary for the survival and function of neurons; thus, sustained reductions of these factors could affect neuronal viability.

The acute effects of BDNF on synaptic plasticity and neurotransmitter release include the release of glutamate, $\gamma$-aminobutyric acid, dopamine, and serotonin [1] although it is perhaps best known for its long-term neurotrophic and neuroprotective effects, which may be key to its putative role in the pathophysiology and treatment of mood disorders. Endogenous neurotrophic factors have traditionally been viewed as increasing cell survival by providing necessary trophic support; however, it is now clear that their survival-promoting effects are largely mediated by inhibiting cell death (apoptosis) cascades [1] Increasing evidence suggests that neurotrophic factors inhibit cell death cascades by activating the extracellularregulated kinase (ERK) signaling pathway [cyclic adenosine monophosphate (cAMP) response element binding (CREB) is directly phosphorylated and activated by phospho-ERK1/2], the phospholipase C (PLC)- $\gamma$ cascade, and the phosphoinositide 3-kinase (PI3K)/Akt pathway. Complementarily, phospho-CREB reductions observed after chronic stress [2] could subsequently downregulate the transcription of some neurotrophic genes such as Bcell lymphoma 2 (bcl-2) and BDNF (fig. 1).

Enhanced bcl-2 expression can offset the potentially deleterious consequences of stress-induced neuronal endangerment, suggesting that pharmacologically induced upregulation of bcl-2 may be useful in treating a variety of disorders associated with endogenous or acquired impairments of cellular resilience. In this context, it is notable that severe stress exacerbates stroke outcome by suppressing bcl-2 expression [3]; for instance, following ischemia, $70 \%$ less bcl-2 mRNA was expressed by mice exposed to aggressive social stress compared with unstressed mice. Furthermore, stress greatly exacerbated the infarct area in control mice, but this effect was not seen in transgenic mice constitutively expressing increased neuronal bcl-2. Similarly, high corticosterone concentrations were significantly correlated with larger infarcts in wild-type mice but not in transgenic mice overexpressing bcl-2. Overall, it is clear that the neurotrophic factor-ERK/mitogen-activated protein (MAP) kinase-bcl-2 signaling cascade plays a critical role in cell survival in the central nervous system (CNS), and that a fine balance is maintained between the levels and activities of cell survival and cell death factors. In parallel, dys- regulation of the necessary coordination between ERK, CREB, and BDNF may also be a key mechanism via which prolonged stress induces atrophy of selective subpopulations of vulnerable neurons and/or distal dendrites. Conceivably, the precise kinetics of ERK and CREB activation could ultimately dictate whether the activated kinases participate in cell death- or survival-promoting pathways.

\section{Lithium Modifies cAMP-Mediated Signal Transduction}

Lithium has complex effects on cAMP-mediated signaling, mainly by elevating basal adenylyl cyclase (AC) activity, but also by reducing receptor-stimulated responses in both preclinical and clinical studies (reviewed in Jope [4]). G proteins modulate intracellular cAMP levels by mediating the effect of neurotransmitters (via extracellular receptors) on AC (which catalyzes the conversion of adenosine triphosphate to cAMP). Indeed, preclinical studies conducted by several independent investigators found that the ability of the receptor-mediated signal to be propagated via AC is decreased after lithium treatment $[4,5]$. These extensive cellular findings are consistent with an animal model in which the cholera toxin induced $G_{s}$ and $G_{\text {olf }}$ protein hyperactivity when injected into the nucleus accumbens of rats; furthermore, cholera toxin-induced hyperactivity was decreased after lithium administration [6], consistent with decreased $\mathrm{G}_{s}$ and/or $G_{\text {olf }}$ activity during lithium treatment (fig. 1). However, while stimulated levels were decreased, there was evidence to suggest increased basal cAMP activity [4]. These complex and potentially regional specific effects on basal activity and stimulated AC activity may arise from the effects of lithium on $G$ proteins and $A C$ subtypes, as well as their relative abundance in different brain regions [4].

The physiologic effects of cAMP are primarily mediated by activation of protein kinase A (PKA), an enzyme that phosphorylates and regulates many proteins including ion channels, cytoskeletal elements, transcription factors, and other enzymes. The transcription factor CREB is one of PKA's major direct targets in the CNS (PKA phosphorylates and activates CREB), and it plays a major role in long-term neuroplasticity (although the cAMP signaling pathway does much more than simply regulate CREB activity). As mentioned above, one of the genes activated by CREB is BDNF, a protein implicated in neuronal survival and synaptic plasticity. A growing 


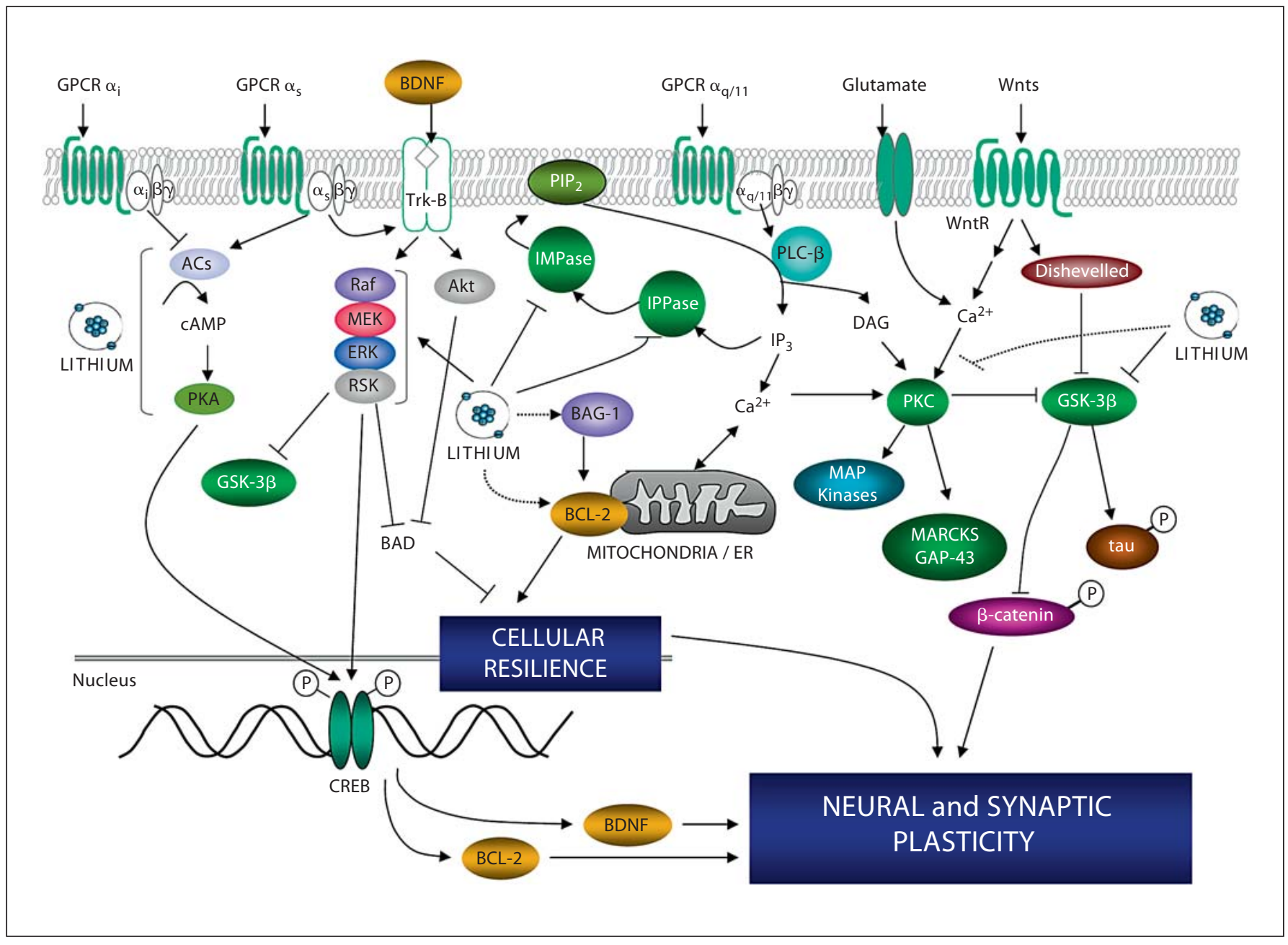

Fig. 1. Neurotrophic and neuroprotective pathways targeted by lithium. BDNF receptor (Trk-B) activation activates the ERK/ MAPK pathway, which inhibits GSK-3 $\beta$ (a critical cellular target and effector for diverse proteins) and bad. This activation increases the expression of nuclear CREB, in turn facilitating the expression of neurotrophic/neuroprotective proteins such as bcl-2 and BDNF itself. Mitochondrial bcl-2 also inhibits pro-apoptotic activation of bad, as well as consequent mitochondrial increases of calcium influx and cytochrome c release. Dysregulated intracellular calcium levels, which may increase the risk of cellular apoptosis, have been associated with the pathophysiology of bipolar disorder. Lithium downregulates ER calcium release via an $\mathrm{IP}_{3} \mathrm{R}$ dependent mechanism, and also increases bcl-2 expression, which improves mitochondrial stability and prevents the activation of apoptotic cascades. IMPase, also directly inhibited by lithium, recycles $\mathrm{IP}_{3}$. In addition, cellular signaling through Wnt glycoproteins and frizzled receptors inhibits GSK-3 $\beta$. Lithium's inhibition of GSK-3 $\beta$ prevents $\beta$-catenin phosphorylation and stimulates its translocation to the nucleus, thus targeting the transcription of specific genes activating neurotrophic effects and synaptogenesis. Different neurotransmitters target receptors coupled to G proteins. Among these, $D_{1}, D_{5}$, and $\beta$-adrenergic receptors are coupled to $\mathrm{G} \alpha$ stimulatory proteins that activate $\mathrm{AC} ; \mathrm{H}_{3}, \mathrm{D}_{2}, \mathrm{D}_{3}$, and $D_{4}$ receptors are coupled to $G \alpha$ inhibitory proteins that inhibit AC; serotonergic, $\alpha_{1}$-adrenergic, $M_{1}, M_{3}$, and $M_{5}$ receptors are coupled to $G_{q / 11}$, which activates PLC. PLC, in turn, hydrolyses $\mathrm{PIP}_{2}$ to $\mathrm{IP}_{3}$ and DAG. DAG activates PKC, which plays a significant role in regulating pre- and postsynaptic aspects of neurotransmission and diverse cellular processes. Lithium also indirectly inhibits $\mathrm{PKC}$. The text provides a complete description of these interactions. Arrows represent 'activation', perpendicular lines represent 'inhibition', and dotted lines represent 'indirect effects'. bad = bcl-2-associated death promoter; bag-1 = bcl-2associated athanogene; GPCR $=\mathrm{G}$-protein-coupled receptors; $\mathrm{IP}_{3} \mathrm{R}=\mathrm{IP}_{3}$ receptor; MARCKS = myristoylated alanine-rich $\mathrm{C}$ kinase substrate; Raf, MEK, ERK, RSK = components of the ERK pathway; Trk-B = tropomyosin receptor kinase. 
body of data suggests that agents that directly modulate the CAMP-PKA-CREB-BDNF signaling cascade may be of particular interest for the development of novel agents to treat depressive disorders [7]. Interestingly, lithium and valproate - both of which are mood stabilizers used in the treatment of bipolar disorder - are known to increase BDNF levels in the brains of rats treated chronically with these drugs [8-10].

\section{Lithium Activates CREB and Increases BDNF Expression}

At therapeutically relevant concentrations, both lithium and valproate activated the ERK/MAP kinase cascade in human neuroblastoma SH-SY5Y cells in vitro [11]; in vivo, these agents activated the same cascade in the hippocampus and frontal cortex areas of the rodent brain [8]. Lithium also activated ERK1/2 after ischemia, and significantly increased cell proliferation in the hippocampal dentate gyrus [12]. Via CREB, the activation of the ERK/MAP kinase pathway initiates the transcription of BDNF, and also induces bcl-2 gene expression. Consistent with the activation of neurotrophic signaling cascades, chronic treatment of rats with therapeutically equivalent lithium or valproate concentrations increased the activation of ribosomal S6 kinase (a member of the MAPK signaling pathway) and CREB, and eventually doubled bcl-2 levels in the frontal cortex, as evidenced by an increased number of bcl-2 immunoreactive cells in layers II and III of the frontal cortex [13-16].

Several preclinical studies have also investigated the effects of lithium on CREB phosphorylation and activity with mixed overall results $[8,17,18]$. For instance, administration of lithium or valproate increased expression of BDNF in the rodent brain [8,9], particularly in the hippocampus [19] and frontal cortex [20]. Therapeutic concentrations of lithium selectively increased levels of exon IV-containing BDNF mRNA, and the activity of BDNF promoter IV [21]. While studies have obtained both positive and negative results after lithium exposure [22, 23], most recent evidence suggests that the neurotrophic effect of lithium in cortical neurons requires BDNF expression [24]. In humans, recent data suggested that the Val66Met BDNF gene polymorphism may be associated with the degree of prophylactic response to lithium; there was a trend for the Met allele genotype to be associated with a higher incidence in positive responders to lithium compared to nonresponders [25]. On the other hand, postmortem studies have noted that individuals with bi- polar disorder treated with lithium had reduced CREB phosphorylation $[26,27]$, although the postmortem instability of phosphorylated proteins is a well-known concern in interpreting such reports.

Finally, the modification of other neurotrophic factors has also been associated with chronic lithium treatment. Changes in NGF and glial cell line-derived neurotrophic factor were observed in a rat model of depression [10], including significant increases of NGF concentrations in the frontal cortex, limbic forebrain, hippocampus, and amygdala of adult rats [28]. Lithium also increased serum and hippocampal NT-3 levels in an animal model of mania [29], and upregulated vascular endothelial growth factor in brain endothelial cells and astrocytes [30]. Interestingly, vascular endothelial growth factor has been implicated in neuronal survival, neurotrophic effects, regeneration, growth, and differentiation. Consistent with these effects on neurotrophic signaling cascades, lithium was found to be neuroprotective in other animal and cell models of neuronal insult and disease [31,32], to promote neurogenesis in the hippocampus of rats, and to increase the regeneration of CNS axons [33].

\section{Lithium Modifies the PI Cascade and Inhibits Protein Kinase C}

Inositol phospholipids play a key role in receptor-mediated signal transduction pathways, and are implicated in a variety of responses including cell division, secretion, neuronal excitability, and responsiveness. The PI pathway is initiated by the activation of G-protein-coupled receptors, which pair neurotransmitter receptors to multiple types of intracellular effector proteins. M1, M2, M3, a1, and serotonin receptors coupled to $\mathrm{G} \alpha_{\mathrm{q} / 11}$ induce PLC, which hydrolyzes phosphatidylinositol-4,5-bisphosphate $\left(\mathrm{PIP}_{2}\right)$ to yield 2 second messengers: inositol-1,4,5-triphosphate $\left(\mathrm{IP}_{3}\right)$ and diacylglycerol (DAG). $\mathrm{IP}_{3}$ and DAG subsequently modulate the activity of many intracellular events. $\mathrm{IP}_{3}$ binds to the $\mathrm{IP}_{3}$ receptor [facilitating the release of calcium from intracellular stores, particularly in the endoplasmic reticulum (ER)] [34, 35], and DAG activates protein kinase $\mathrm{C}$ (PKC) (fig. 1).

The direct effect of lithium on inositol monophosphatase (IMPase) [36, 37] and, secondarily, on inositol polyphosphate 1-phosphatase $[38,39]$ led to the inositol depletion hypothesis of lithium action [40,41]. This hypothesis suggests that lithium exerts its mood-stabilizing effects by inhibiting IMPase, thereby decreasing inositol concentrations and the amount of $\mathrm{PIP}_{2}$ available for signal- 
ing cascades that rely upon this pathway; this includes, but is not limited to, the neurotrophin signaling pathways, the receptor tyrosine kinase pathways, and the Gprotein-mediated signaling, all of which rely on PI availability [40]. The brain is believed to be particularly sensitive to lithium, due to the relatively poor penetration of inositol across the blood-brain barrier [40] or to a reduced ability of specific neuronal populations to transport inositol across their cell membranes [42]. In fact, it has been shown that lithium, carbamazepine, and valproate inhibit sodium myo-inositol transporter 1 (SMIT1) on astrocyte-like cells at therapeutically relevant concentrations [43]. More recently, homozygote knockout mice for the SMIT1 gene (receiving inositol supplementation) appeared to behave similarly to lithium-treated animals in seizure and depression models [44]. However, it has also been reported that reduced intracellular inositol in the brains of SMIT1 knockout mice had no effect on PI levels [45], suggesting that inositol depletion may not have major effects on PI-mediated signaling in this paradigm. Importantly, it has also been reported that the content of SMIT1 mRNA in neutrophils of untreated patients with bipolar I disorder is higher than in a control population while the levels are reduced in treated versus control and untreated bipolar subjects [46]. Although there are some limitations associated with the peripheral nature of the cells studied (that may not reflect brain pathophysiology) and the post hoc origin of the analysis, this hypothesis generating research confirms the need to better understand the role that PI pathways play in bipolar disorder.

As mentioned above, lithium interacts with the PI/ PKC pathway by inhibiting IMPase, resulting in decreased free myo-inositol and the subsequent production of DAG, with the downstream effect of also decreasing PKC levels and activity (in some cell culture models, there is evidence of a biphasic action showing initial PKC activation followed by downregulation). PKC is an omnipresent enzyme, and highly enriched in the brain, where it regulates both pre- and postsynaptic aspects of neurotransmission [47], as well as several cellular processes. These include the stimulation of transmembrane glucose transport, secretion, exocytosis, smooth muscle contraction, gene expression, modulation of ion conductance, cell proliferation, and desensitization of extracellular receptors [47]. Interestingly, certain PKC isoforms phosphorylate and inactivate glycogen synthase kinase 3 (GSK-3) in vitro [48] (see below).

PKC isoforms differ in their structure, subcellular localization, tissue specificity, mode of activation, and sub- strate specificity. It is important to note that chronic lithium treatment decreases the level of PKC isozymes $\alpha$ and $\varepsilon$ [49-51] in cells as well as in treated rodents (in part due to the ability of lithium to inhibit IMPase [32, 49]). Following chronic treatment in rats, lithium also decreases the levels and phosphorylation of myristoylated alaninerich C kinase substrate, a major PKC substrate that has been implicated in signaling and neuroplastic events associated with cytoskeletal architecture [52, 53].

Taken together with the abundant preclinical biochemical and behavioral data supporting the notion that PKC activity may mediate manic-like behaviors, the inhibition of PKC by lithium led to a series of hypothesisdriven clinical studies investigating this relationship. The first study of a fairly selective PKC inhibitor in humans was a small, open-label trial of tamoxifen, which was found to produce a greater than $50 \%$ decrease in manic symptoms in 5 of 7 subjects [54]. Furthermore, this effect was very recently confirmed in 2 double-blind, placebocontrolled studies of acutely manic patients by the original researchers [55], and by an independent group of investigators [56].

\section{Action of Lithium on the Arachidonic Acid Signaling Cascade}

Lithium also plays an important role in the arachidonic acid (AA) cascade. AA is an important mediator of second messenger pathways in the brain $[57,58]$, and is released from membrane phospholipids via the activation of receptor/G-protein-initiated phospholipase A2 (PLA2) [59]. This results in AA release from the cellular membrane, and cyclooxygenase-mediated production of eicosanoid metabolites such as prostaglandins and thromboxanes. Due to their lipid-permeable nature, these metabolites mediate numerous subsequent intracellular responses as well as transynaptic responses. In rats, treatment with lithium or valproate resulted in selective reductions in the turnover rate in the brain phospholipids of AA [60-62]. In the case of lithium, an $80 \%$ reduction of AA turnover was observed. In addition, lithium decreased the gene expression and protein levels of an AAspecific PLA2 (specifically, cytosolic PLA2) [63, 64], as well as cyclooxygenase 2 protein levels [65]. These findings suggest that the effects of mood stabilizers on cell membranes - and specifically on AA turnover - might be relevant to the pharmacological action of mood stabilizers $[58,62]$. 


\section{Competition of Lithium with Magnesium}

Lithium also inhibits some enzymes through direct competition with magnesium, an often-required cofactor $[5,66,67]$. At least 4 related phosphomonoesterases are significantly inhibited at therapeutic serum lithium concentrations [68] (0.6-1.2 mM); in mammals, this group of magnesium-dependent, lithium-sensitive phosphatases includes inositol polyphosphate 1-phosphatase and IMPase (discussed above), fructose 1,6-bisphosphatase, bisphosphate nucleotidase [69], and phosphoglucomutase [70-73]. A significant amount of research has focused on IMPase as a possible therapeutically relevant target of lithium inhibition, predominantly due to the role this enzyme plays in CNS functions [74].

\section{GSK-3 Inhibition by Lithium}

GSK-3 is a serine/threonine kinase that regulates diverse cellular processes and directly regulates cell apoptosis. It is key to glycogen synthesis, gene transcription, synaptic plasticity, apoptosis (cell death), cellular structure and resilience, and the circadian cycle [75], all of which are significantly implicated in the pathophysiology of severe recurrent mood disorders. In 1996, GSK-3 was identified as the lithium target responsible for developmental effects in Xenopus embryos [76], but more recently, further evidence substantially supports the claim that GSK-3 is one of the therapeutic targets of lithium.

GSK-3 $\beta$ activation functionally inhibits CREB, $\beta$ catenin (an important component of memory consolidation), and other survival-promoting transcription factors. GSK-3 is also directly regulated by signals originating from a number of different signaling pathways including the Wnt pathway, the PI3K pathway, PKA, and PKC. Its other targets include transcription factors like c-Jun, proteins bound to microtubules (Tau, microtubule-associated protein $1 \mathrm{~B}$, kinesin light chain), cell cycle mediators (cyclin D), and metabolic regulators (glycogen synthase, pyruvate dehydrogenase) [77]. GSK-3 also directly regulates the dopaminergic, glutamatergic, and serotonergic neurotransmitter systems (reviewed in Beaulieu et al. [78] and Jope and Roh [79]). It is interesting to note that increases in phosphorylated GSK-3 levels have also been observed by 5-HT1A receptor activation, 5HT2 receptor blockage [80], and by atypical antipsychotic administration (with $\mathrm{D}_{2}$ but also 5-HT2A blocking activity) in experiments with mice [81].
Early studies suggested that peripheral administration of lithium inhibited GSK-3 in the brains of 7-day-old rats [82], as well as during long-term treatment at therapeutic concentrations. Investigators also found that 9 days of lithium treatment in rats (at a mean serum concentration of $0.8 \mathrm{mM}$ ) increased cytosolic protein levels of $\beta$-catenin, a transcription factor directly regulated by GSK-3 [83]. Small but significant decreases in $\beta$-catenin mRNA levels (reflecting cellular compensation) accompanied this increase, further suggesting that lithium exerted its actions post-translationally by inhibiting GSK-3 [83]. Similar findings have noted that chronic lithium does indeed activate $\beta$-catenin-dependent transcription in the mouse brain [84] (fig. 1).

Because GSK-3 inhibition is commonly associated with the neurotrophic effects of different survival factors, this kinase may mediate the neuroprotective effects of lithium. In fact, GSK-3 inhibition directly influences gene transcription, leading to anti-apoptotic effects and improved cell structural stability [85]. Notably, diverse studies have noted that GSK-3 is downregulated by lithi$\mathrm{um}$, thereby inducing direct neuronal protection against different injuries [86], and providing new insights into the neurotrophic effects of lithium (reviewed in Jope [4]). Furthermore, recent evidence suggests that the behavioral effects of lithium, at least in rodent models, may also be due to GSK-3 inhibition. For instance, the administration of GSK-3 inhibitors resulted in antidepressant-like effects in the forced swim test paradigm following either peripheral lithium administration in rats [71], or lithium administration in mice [84], including intracerebral ventricle injections in mice [87]. While initial reports suggested that knocking out a single copy of the GSK- $3 \beta$ gene in mice resulted in antidepressant-like effects analogous to lithium administration [84], these findings were subsequently not confirmed in mice of a different genetic background [88].

More recently, transgenic mice overexpressing $\beta$ catenin demonstrated changes comparable to those observed following lithium administration. These changes included decreased immobility time in the forced swim test and the inhibition of D-amphetamine-induced hyperlocomotion. Such findings are consistent with the notion that the behavioral effects of lithium are mediated via direct inhibition of GSK-3 and the consequent increase in $\beta$-catenin [89]. 


\section{Effect of Lithium on bcl-2 and Mitochondrial Function}

The regulatory effects of lithium on apoptosis-controlling proteins appear to occur in both the mitochondria [35] and the ER [90-92]. Relatedly, altered calcium dynamics are the most reproducible biological measure in the pathophysiology of bipolar disorder (reviewed in Quiroz et al. [35] and Warsh et al. [93]). A large movement of calcium into the mitochondria will exceed the mitochondrial capacity to export protons, potentially interrupting adenosine triphosphate synthesis and the activation of the permeability transition pore with release of cytochrome c, thus initiating cellular apoptosis [35]. In addition, excessive production of reactive oxygen species (or free radicals) triggered by mitochondrial dysfunction may lead to oxidative stress, regardless of whether or not this is related to lower antioxidant capacity.

Mitochondria are well known for their critical role in regulating energy production via oxidative phosphorylation, regulation of intracellular calcium, and as critical mediators of cellular apoptosis. Increasing evidence suggests that they may also be integrally involved in general processes of synaptic plasticity [35]. As noted previously, the bcl-2 family of proteins includes both pro- and antiapoptotic proteins embedded in the inner mitochondrial membrane, although they may also be present in nuclear membranes and in the ER. Therefore, expression and/or activation of pro-apoptotic bcl-2 family members (e.g. bad and bax) may increase mitochondrial membrane permeability, while anti-apoptotic members (e.g. bcl-2 and bcl-xl) have the opposite effect [35]. Interestingly, lithium also increases the expression of bcl-2-associated athanogene (bag-1), which is known to attenuate glucocorticoid receptor nuclear translocation, to activate the ERK/MAP kinases, and to potentiate the anti-apoptotic functions of bcl-2 [94] (fig. 1).

Several biochemical changes have been hypothesized to account for the neurotrophic properties of lithium against oxidative stress and apoptosis, including its ability to regulate bcl-2. bcl-2 levels were found to be robustly increased in the frontal cortex after lithium treatment, particularly in layers II and III [13]. Also, long-term lithium treatment of cultured cerebellar granule cells induced concentration-dependent decreases in p53 mRNA levels as well as bax protein levels (both of which are proapoptotic), while acute treatment had no effect. Conversely, bcl-2 mRNA and protein levels increased considerably with long-term lithium treatment, and the bcl-2/ bax protein level ratio increased approximately 5 -fold af- ter lithium treatment for 5-7 days [16]. Furthermore, chronic treatment with lithium in drinking water prevented the aluminum-induced translocation of cytochrome c, upregulating bcl-2 and bcl-xl, and thus reducing DNA damage. As noted previously, animal models have also noted a relationship between stress and bcl-2 expression.

\section{Human Studies Demonstrating the Neurotrophic Effects of Lithium}

While the preclinical data demonstrating that lithium has neurotrophic and neuroprotective effects are striking, considerable caution must be exercised in extrapolating these data to human clinical situations, where the data regarding the neurotrophic effects of lithium are considerably more limited.

The most replicated finding from structural neuroimaging studies is the association between lithium treatment and increased gray matter (GM) volume in brain areas implicated in emotional processing and cognitive control, including the anterior cingulate gyrus, amygdala, and hippocampus $[95,96]$. In structural studies, reanalyzed data demonstrated approximately $40 \%$ reductions in subgenual prefrontal cortex volumes in individuals with familial mood disorders [97]. These investigators also studied glial cell densities in a small number of individuals with major depressive disorder and found that they exhibited reduced glial cell densities; in contrast, in individuals with bipolar disorder, only those who had discontinued chronic treatment with lithium or valproate exhibited similar reductions [98], suggesting that these mood stabilizers conferred neuroprotective properties.

More recently, a longitudinal high-resolution volumetric MRI study of well-characterized, medication-free individuals with bipolar depression compared total brain GM, prefrontal GM, and left subgenual GM at baseline and after 4 weeks of blinded lithium treatment [93]. Significant increases in total brain GM were observed after chronic lithium administration. Furthermore, regionspecific analyses revealed significant differences between lithium responders ( $>50 \%$ decrease in Hamilton Depression Rating Scale scores) and nonresponders; only the lithium responders had significant increases in GM volume in the prefrontal cortex and a trend level increase in the left subgenual prefrontal cortex volume [99]. Another study found that individuals with bipolar disorder not treated with lithium had significantly reduced left ante- 
rior cingulate volumes compared to healthy volunteers and lithium-treated patients [100]. Additional MRI studies compared GM and white matter volumes in untreated and lithium-treated patients with bipolar disorder and healthy controls, and found that total GM volume was significantly higher in individuals treated with lithium than in untreated patients and healthy controls [101]. GM density was also found to be significantly greater in diffuse cortical regions in individuals with bipolar disorder who were treated with lithium relative to healthy controls [102]. Interestingly, total hippocampal volume was also significantly greater in lithium-treated patients with bipolar disorder compared with healthy controls or unmedicated patients (by 10 and $14 \%$, respectively) [103], also shown in both short-term (1-8 weeks) and long-term lithium treatment in drug-naïve bipolar subjects [104, 105].

\section{Future Directions: The Neurotrophic Effects of Lithium Might Be Relevant in the Treatment of Other Neuropsychiatric Disorders}

As the evidence reviewed above makes clear, lithium has garnered considerable interest as a neuroprotective drug. Data from many in vitro models have evaluated the properties of lithium against excitotoxicity or apoptosis, including glutamate-induced excitotoxicity, $\mathrm{C}_{2}$-ceramide-induced apoptosis, oxygen and glucose deprivation, aluminum, low potassium medium, ouabain-induced LDH, b-bungarotoxin, and pilocarpine-induced mossy fiber sprouting (reviewed in Bowley et al. [98]). This evidence has prompted a considerable amount of research in an effort to clarify the pathophysiological role of the neuroprotective properties of lithium in animal models of several human diseases. These include models of brain ischemia, injury (especially spinal cord and optic nerve injury), infection, irradiation, neurodegeneration and neuroinflammation, Alzheimer's disease, Huntington's disease, amyotrophic lateral sclerosis, HIV-associated cognitive impairments, spinocerebellar ataxia, and cranial irradiation (reviewed in Machado-Vieira et al. [106]). Interestingly, lithium also appears to stimulate the biogenesis of mitochondria in the CNS and spinal cord, thus inducing neurogenesis and neuronal differentiation also in subjects with amyotrophic lateral sclerosis [107]. Promising preliminary results were obtained from these preclinical studies, leading to current epidemiological and clinical studies addressing the putative use of lithium in human populations. While the results are still to come, these are expected to significantly improve our understanding of these devastating diseases.

\section{Conclusions}

Recent studies investigating the robust neurotrophic and neuroprotective effects of lithium have identified novel, exciting, and promising targets. Due to the accumulating data linking lithium mechanisms of action with the enhancement of neurotrophic cascades and pathways, we are optimistic that this evidence will ultimately lead to a better understanding of clinically relevant pathophysiological targets, and the consequent development of improved treatments for those who suffer from these devastating psychiatric and neurodegenerative disorders.

\section{Acknowledgement}

We would like to acknowledge the outstanding editorial assistance of Ioline Henter, MA.

\section{References}

1 Du J, Gould TD, Manji HK: Neurotrophic signaling in mood disorders; in Finkel T, Gutkind JS (eds): Signal Transduction and Human Disease. Hoboken, Wiley, 2003, pp 411-446.

-2 Trentani A, Kuipers SD, Ter Horst GJ, Den Boer JA: Selective chronic stress-induced in vivo erk1/2 hyperphosphorylation in medial prefrontocortical dendrites: implications for stress-related cortical pathology? Eur J Neurosci 2002;15:1681-1691.

\footnotetext{
-3 DeVries AC, Joh HD, Bernard O, Hattori K, Hurn PD, Traystman RJ, Alkayed NJ: Social stress exacerbates stroke outcome by suppressing bcl-2 expression. Proc Natl Acad Sci USA 2001;98:11824-11828.

4 Jope RS: A bimodal model of the mechanism of action of lithium. Mol Psychiatry 1999;4: $21-25$.

5 Gould TD, Chen G, Manji HK: Mood stabilizer psychopharmacology. Clin Neurosci Res 2002;2:193-212.
}

\footnotetext{
6 Kofman O, Li PP, Warsh JJ: Lithium, but not carbamazepine, potentiates hyperactivity induced by intra-accumbens cholera toxin. Pharmacol Biochem Behav 1998;59:191200.

7 Manji HK, Duman RS: Impairments of neuroplasticity and cellular resilience in severe mood disorders: implications for the development of novel therapeutics. Psychopharmacol Bull 2001;35:5-49.
} 
$>8$ Einat H, Yuan P, Gould TD, Li J, Du J, Zhang L, Manji HK, Chen G: The role of the extracellular signal-regulated kinase signaling pathway in mood modulation. J Neurosci 2003;23:7311-7316.

9 Fukumoto T, Morinobu S, Okamoto Y, Kagaya A, Yamawaki S: Chronic lithium treatment increases the expression of brain-derived neurotrophic factor in the rat brain. Psychopharmacology (Berl) 2001;158:100106.

10 Angelucci F, Aloe L, Jimenez-Vasquez P, Mathe AA: Lithium treatment alters brain concentrations of nerve growth factor, brainderived neurotrophic factor and glial cell line-derived neurotrophic factor in a rat model of depression. Int J Neuropsychopharmacol 2003;6:225-231.

-11 Yuan PX, Huang LD, Jiang YM, Gutkind JS, Manji HK, Chen G: The mood stabilizer valproic acid activates mitogen-activated protein kinases and promotes neurite growth. J Biol Chem 2001;276:31674-31683.

- 12 Yan XB, Hou HL, Wu LM, Liu J, Zhou JN: Lithium regulates hippocampal neurogenesis by erk pathway and facilitates recovery of spatial learning and memory in rats after transient global cerebral ischemia. Neuropharmacology 2007;53:487-495.

-13 Chen G, Zeng WZ, Yuan PX, Huang LD, Jiang YM, Zhao ZH, Manji HK: The moodstabilizing agents lithium and valproate robustly increase the levels of the neuroprotective protein bcl-2 in the CNS. J Neurochem 1999;72:879-882.

14 Manji HK, Chen G: Pkc, map kinases and the bcl-2 family of proteins as long-term targets for mood stabilizers. Mol Psychiatry 2002; 7(suppl 1):S46-S56.

-15 Chen G, Huang LD, Zeng WZ, Manji HK: Mood stabilizers regulate cytoprotective and mRNA-binding proteins in the brain: longterm effects on cell survival and transcript stability. Int J Neuropsychopharmacol 2001; 4:47-64.

16 Chen RW, Chuang DM: Long-term lithium treatment suppresses 553 and bax expression but increases bcl-2 expression. A prominent role in neuroprotection against excitotoxicity. J Biol Chem 1999;274:6039-6042.

17 Ozaki N, Chuang DM: Lithium increases transcription factor binding to AP-1 and cyclic AMP-responsive element in cultured neurons and rat brain. J Neurochem 1997;69: 2336-2344.

-18 Tardito D, Tiraboschi E, Kasahara J, Racagni G, Popoli M: Reduced CREB phosphorylation after chronic lithium treatment is associated with down-regulation of CaM kinase IV in rat hippocampus. Int J Neuropsychopharmacol 2007;10:491-496.

-19 Frey BN, Andreazza AC, Rosa AR, Martins MR, Valvassori SS, Reus GZ, Hatch JP, Quevedo J, Kapczinski F: Lithium increases nerve growth factor levels in the rat hippocampus in an animal model of mania. Behav Pharmacol 2006;17:311-318.
20 Jacobsen JP, Mork A: The effect of escitalopram, desipramine, electroconvulsive seizures and lithium on brain-derived neurotrophic factor mRNA and protein expression in the rat brain and the correlation to 5 -HT and 5-HIAA levels. Brain Res 2004;1024: 183-192.

-21 Yasuda S, Liang MH, Marinova Z, Yahyavi A, Chuang DM: The mood stabilizers lithium and valproate selectively activate the promoter IV of brain-derived neurotrophic factor in neurons. Mol Psychiatry 2009; 14 51-59.

22 McQuillin A, Rizig M, Gurling HM: A microarray gene expression study of the molecular pharmacology of lithium carbonate on mouse brain mRNA to understand the neurobiology of mood stabilization and treatment of bipolar affective disorder. Pharmacogenet Genomics 2007;17:605-617.

23 Hammonds MD, Shim SS, Feng P, Calabrese JR: Effects of subchronic lithium treatment on levels of BDNF, Bcl-2 and phospho-CREB in the rat hippocampus. Basic Clin Pharmacol Toxicol 2007;100:356-359.

24 Hashimoto R, Takei N, Shimazu K, Christ L, Lu B, Chuang DM: Lithium induces brainderived neurotrophic factor and activates TrkB in rodent cortical neurons: an essential step for neuroprotection against glutamate excitotoxicity. Neuropharmacology 2002;43. 1173-1179.

25 Rybakowski JK, Suwalska A, Skibinska M, Szczepankiewicz A, Leszczynska-Rodziewicz A, Permoda A, Czerski PM, Hauser J: Prophylactic lithium response and polymorphism of the brain-derived neurotrophic factor gene. Pharmacopsychiatry 2005;38: $166-170$

26 Stewart RJ, Chen B, Dowlatshahi D, MacQueen GM, Young LT: Abnormalities in the cAMP signaling pathway in post-mortem brain tissue from the Stanley Neuropathology Consortium. Brain Res Bull 2001;55: 625-629.

27 Young LT, Bezchlibnyk YB, Chen B, Wang JF, MacQueen GM: Amygdala cyclic adenosine monophosphate response element binding protein phosphorylation in patients with mood disorders: effects of diagnosis, suicide, and drug treatment. Biol Psychiatry 2004;55: 570-577.

28 Hellweg R, Lang UE, Nagel M, Baumgartner A: Subchronic treatment with lithium increases nerve growth factor content in distinct brain regions of adult rats. Mol Psychiatry 2002;7:604-608.

29 Walz JC, Frey BN, Andreazza AC, Cereser KM, Cacilhas AA, Valvassori SS, Quevedo J, Kapczinski F: Effects of lithium and valproate on serum and hippocampal neurotrophin-3 levels in an animal model of mania. J Psychiatr Res 2008;42:416-421.

30 Warner-Schmidt JL, Duman RS: VEGF as a potential target for therapeutic intervention in depression. Curr Opin Pharmacol 2008;8: 14-19.
31 Chuang DM, Chen R, Chalecka-Franaszek E, Ren M, Hashimoto R, Senatorov V, Kanai H, Hough C, Hiroi T, Leeds P: Neuroprotective effects of lithium in cultured cells and animal models of diseases. Bipolar Disord 2002;4:129-136.

>32 Manji HK, Moore GJ, Chen G: Lithium at 50: have the neuroprotective effects of this unique cation been overlooked? Biol Psychiatry 1999;46:929-940.

33 Huang X, Wu DY, Chen G, Manji H, Chen DF: Support of retinal ganglion cell survival and axon regeneration by lithium through a bcl-2-dependent mechanism. Invest Ophthalmol Vis Sci 2003;44:347-354.

>34 Gould TD, Manji HK: Signaling networks in the pathophysiology and treatment of mood disorders. J Psychosom Res 2002;53:687697.

-35 Quiroz JA, Gray NA, Kato T, Manji HK: Mitochondrially mediated plasticity in the pathophysiology and treatment of bipolar disorder. Neuropsychopharmacology 2008; 33:2551-2565.

>36 Naccarato WF, Ray RE, Wells WW: Biosynthesis of myo-inositol in rat mammary gland. Isolation and properties of the enzymes. Arch Biochem Biophys 1974;164:194-201.

37 Hallcher LM, Sherman WR: The effects of lithium ion and other agents on the activity of myo-inositol-1-phosphatase from bovine brain. J Biol Chem 1980;255:10896-10901.

38 Ragan CI, Watling KJ, Gee NS, Aspley S, Jackson RG, Reid GG, Baker R, Billington DC, Barnaby RJ, Leeson PD: The dephosphorylation of inositol 1,4-bisphosphate to inositol in liver and brain involves two distinct $\mathrm{Li}+$-sensitive enzymes and proceeds via inositol 4phosphate. Biochem J 1988;249:143-148.

39 Inhorn RC, Majerus PW: Properties of inositol polyphosphate 1-phosphatase. J Biol Chem 1988;263:14559-14565.

40 Berridge MJ, Downes CP, Hanley MR: Neural and developmental actions of lithium: a unifying hypothesis. Cell 1989;59:411-419.

41 Berridge MJ, Downes CP, Hanley MR: Lithium amplifies agonist-dependent phosphatidylinositol responses in brain and salivary glands. Biochem J 1982;206:587-595.

-42 Gani D, Downes CP, Batty I, Bramham J: Lithium and myo-inositol homeostasis. Biochim Biophys Acta 1993;1177:253-269.

43 Lubrich B, van Calker D: Inhibition of the high affinity myo-inositol transport system: a common mechanism of action of antibipolar drugs? Neuropsychopharmacology 1999; 21:519-529

-44 Bersudsky Y, Shaldubina A, Agam G, Berry GT, Belmaker RH: Homozygote inositol transporter knockout mice show a lithiumlike phenotype. Bipolar Disord 2008;10: 453-459.

45 Berry GT, Buccafusca R, Greer JJ, Eccleston E: Phosphoinositide deficiency due to inositol depletion is not a mechanism of lithium action in brain. Mol Genet Metab 2004;82: 87-92. 
-46 Willmroth F, Drieling T, Lamla U, Marcushen M, Wark HJ, van Calker D: Sodium-myoinositol co-transporter (SMIT-1) mRNA is increased in neutrophils of patients with bipolar 1 disorder and down-regulated under treatment with mood stabilizers. Int J Neuropsychopharmacol 2007;10:63-71.

47 Nishizuka Y: Intracellular signaling by hydrolysis of phospholipids and activation of protein kinase C. Science 1992;258:607614.

-48 Goode N, Hughes K, Woodgett JR, Parker PJ: Differential regulation of glycogen synthase kinase-3 beta by protein kinase c isotypes. J Biol Chem 1992;267:16878-16882.

49 Manji HK, Bersudsky Y, Chen G, Belmaker RH, Potter WZ: Modulation of protein kinase $\mathrm{C}$ isozymes and substrates by lithium: the role of myo-inositol. Neuropsychopharmacology 1996;15:370-381.

- 50 Manji HK, Etcheberrigaray R, Chen G, Olds JL: Lithium decreases membrane-associated protein kinase $\mathrm{C}$ in hippocampus: selectivity for the alpha isozyme. J Neurochem 1993;61: 2303-2310.

51 Li X, Jope RS: Selective inhibition of the expression of signal transduction proteins by lithium in nerve growth factor-differentiated PC12 cells. J Neurochem 1995;65:25002508.

- 52 Lenox RH, Watson DG, Patel J, Ellis J: Chronic lithium administration alters a prominent PKC substrate in rat hippocampus. Brain Res 1992;570:333-340.

-53 Watson DG, Lenox RH: Chronic lithium-induced down-regulation of MARCKS in immortalized hippocampal cells: potentiation by muscarinic receptor activation. J Neurochem 1996;67:767-777.

54 Bebchuk JM, Arfken CL, Dolan-Manji S, Murphy J, Hasanat K, Manji HK: A preliminary investigation of a protein kinase $\mathrm{C}$ inhibitor in the treatment of acute mania. Arch Gen Psychiatry 2000;57:95-97.

-55 Zarate CA, Singh JB, Carlson PJ, Quiroz JA, Jolkovsky L, Luckenbaugh DA, Manji HK: Efficacy of a protein kinase C inhibitor (tamoxifen) in the treatment of acute mania: a pilot study. Bipolar Disord 2007;9:561570.

-56 Yildiz A, Guleryuz S, Ankerst DP, Ongur D, Renshaw PF: Protein kinase $C$ inhibition in the treatment of mania: a double-blind, placebo-controlled trial of tamoxifen. Arch Gen Psychiatry 2008;65:255-263.

57 Axelrod J, Burch RM, Jelsema CL: Receptormediated activation of phospholipase A2 via GTP-binding proteins: arachidonic acid and its metabolites as second messengers. Trends Neurosci 1988;11:117-123.

-58 Rapoport SI: In vivo fatty acid incorporation into brain phosholipids in relation to plasma availability, signal transduction and membrane remodeling. J Mol Neurosci 2001;16: 243-261; discussion 279-284.
59 Axelrod J: Phospholipase A2 and G proteins. Trends Neurosci 1995;18:64-65.

60 Chang MC, Contreras MA, Rosenberger TA, Rintala JJ, Bell JM, Rapoport SI: Chronic valproate treatment decreases the in vivo turnover of arachidonic acid in brain phospholipids: a possible common effect of mood stabilizers. J Neurochem 2001;77:796-803.

61 Chang MC, Grange E, Rabin O, Bell JM, Allen DD, Rapoport SI: Lithium decreases turnover of arachidonate in several brain phospholipids. Neurosci Lett 1996;220:171174.

62 Rapoport SI, Bosetti F: Do lithium and anticonvulsants target the brain arachidonic acid cascade in bipolar disorder? Arch Gen Psychiatry 2002;59:592-596.

63 Chang MC, Jones CR: Chronic lithium treatment decreases brain phospholipase A2 activity. Neurochem Res 1998;23:887-892.

64 Rintala J, Seemann R, Chandrasekaran K, Rosenberger TA, Chang L, Contreras MA, Rapoport SI, Chang MC: $85 \mathrm{kDa}$ cytosolic phospholipase A2 is a target for chronic lithium in rat brain. Neuroreport 1999;10:38873890.

65 Bosetti F, Rintala J, Seemann R, Rosenberger TA, Contreras MA, Rapoport SI, Chang MC: Chronic lithium downregulates cyclooxygenase-2 activity and prostaglandin $\mathrm{E}(2)$ concentration in rat brain. Mol Psychiatry 2002;7:845-850

66 Amari L, Layden B, Rong Q, Geraldes CF, Mota de Freitas D: Comparison of fluorescence, (31)P NMR, and (7)Li NMR spectroscopic methods for investigating $\mathrm{Li}(+) /$ $\mathrm{Mg}(2+)$ competition for biomolecules. Anal Biochem 1999;272:1-7.

67 Ryves WJ, Harwood AJ: Lithium inhibits glycogen synthase kinase- 3 by competition for magnesium. Biochem Biophys Res Commun 2001;280:720-725.

68 Davies SP, Reddy H, Caivano M, Cohen P: Specificity and mechanism of action of some commonly used protein kinase inhibitors. Biochem J 2000;351:95-105.

69 York JD, Ponder JW, Majerus PW: Definition of a metal-dependent/Li(+)-inhibited phosphomonoesterase protein family based upon a conserved three-dimensional core structure. Proc Natl Acad Sci USA 1995;92:51495153.

70 Nordenberg J, Kaplansky M, Beery E, Klein S, Beitner R: Effects of lithium on the activities of phosphofructokinase and phosphoglucomutase and on glucose-1,6-diphosphate levels in rat muscles, brain and liver. Biochem Pharmacol 1982;31:1025-1031.

71 Rhyu GI, Ray WJ Jr, Markley JL: Enzymebound intermediates in the conversion of glucose 1-phosphate to glucose 6-phosphate by phosphoglucomutase. Phosphorus NMR studies. Biochemistry 1984;23:252-260.

72 Ray WJ Jr, Szymanki ES, Ng L: The binding of lithium and of anionic metabolites to phosphoglucomutase. Biochim Biophys Acta 1978;522:434-442.
73 Masuda CA, Xavier MA, Mattos KA, Galina A, Montero-Lomeli M: Phosphoglucomutase is an in vivo lithium target in yeast. J Biol Chem 2001;276:37794-37801.

74 Gould TD, Einat H, Bhat R, Manji HK: AR-A014418, a selective GSK-3 inhibitor, produces antidepressant-like effects in the forced swim test. Int J Neuropsychopharmacol 2004;7:387-390.

75 Jope RS: Lithium and GSK-3: one inhibitor, two inhibitory actions, multiple outcomes. Trends Pharmacol Sci 2003;24:441-443.

76 Klein PS, Melton DA: A molecular mechanism for the effect of lithium on development. Proc Natl Acad Sci USA 1996;93: 8455-8459.

77 Gould TD, Zarate CA, Manji HK: Glycogen synthase kinase-3: a target for novel bipolar disorder treatments. J Clin Psychiatry 2004; 65:10-21.

78 Beaulieu JM, Gainetdinov RR, Caron MG: Akt/GSK3 signaling in the action of psychotropic drugs. Annu Rev Pharmacol Toxicol 2009;49:327-347.

79 Jope RS, Roh MS: Glycogen synthase kinase3 (GSK3) in psychiatric diseases and therapeutic interventions. Curr Drug Targets 2006;7:1421-1434

80 Li X, Bijur GN, Jope RS: Glycogen synthase kinase-3beta, mood stabilizers, and neuroprotection. Bipolar Disord 2002;4:137-144.

-81 Li X, Rosborough KM, Friedman AB, Zhu W, Roth KA: Regulation of mouse brain glycogen synthase kinase- 3 by atypical antipsychotics. Int J Neuropsychopharmacol 2007; 10:7-19.

-82 Munoz-Montano JR, Moreno FJ, Avila J, Diaz-Nido J: Lithium inhibits Alzheimer's disease-like tau protein phosphorylation in neurons. FEBS Lett 1997;411:183-188.

83 Gould TD, Chen G, Manji HK: In vivo evidence in the brain for lithium inhibition of glycogen synthase kinase-3. Neuropsychopharmacology 2004;29:32-38.

84 O’Brien WT, Harper AD, Jove F, Woodgett JR, Maretto S, Piccolo S, Klein PS: Glycogen synthase kinase-3beta haploinsufficiency mimics the behavioral and molecular effects of lithium. J Neurosci 2004;24:6791-6798.

85 Chin PC, Majdzadeh N, D’Mello SR: Inhibition of GSK3beta is a common event in neuroprotection by different survival factors. Brain Res Mol Brain Res 2005;137:193-201.

-86 Bijur GN, De Sarno P, Jope RS: Glycogen synthase kinase-3beta facilitates staurosporineand heat shock-induced apoptosis. Protection by lithium. J Biol Chem 2000;275: 7583-7590.

87 Kaidanovich-Beilin O, Milman A, Weizman A, Pick CG, Eldar-Finkelman H: Rapid antidepressive-like activity of specific glycogen synthase kinase- 3 inhibitor and its effect on beta-catenin in mouse hippocampus. Biol Psychiatry 2004;55:781-784. 
88 Bersudsky Y, Shaldubina A, Kozlovsky N, Woodgett JR, Agam G, Belmaker RH: Glycogen synthase kinase-3beta heterozygote knockout mice as a model of findings in postmortem schizophrenia brain or as a model of behaviors mimicking lithium action: negative results. Behav Pharmacol 2008; 19:217-224.

-89 Gould TD, Einat H, O’Donnell KC, Picchini AM, Schloesser RJ, Manji HK: Beta-catenin overexpression in the mouse brain phenocopies lithium-sensitive behaviors. Neuropsychopharmacology 2007;32:2173-2183.

90 Ghribi O, Herman MM, Spaulding NK, Savory J: Lithium inhibits aluminum-induced apoptosis in rabbit hippocampus, by preventing cytochrome $\mathrm{c}$ translocation, $\mathrm{Bcl}-2$ decrease, Bax elevation and caspase-3 activation. J Neurochem 2002;82:137-145.

-91 Leng Y, Liang MH, Ren M, Marinova Z, Leeds P, Chuang DM: Synergistic neuroprotective effects of lithium and valproic acid or other histone deacetylase inhibitors in neurons: roles of glycogen synthase kinase-3 inhibition. J Neurosci 2008;28:2576-2588.

92 Yeste M, Alvira D, Verdaguer E, Tajes M, Folch J, Rimbau V, Pallas M, Camins A: Evaluation of acute antiapoptotic effects of $\mathrm{Li}+$ in neuronal cell cultures. J Neural Transm 2007;114:405-416.

93 Warsh JJ, Andreopoulos S, Li PP: Role of intracellular calcium signaling in the pathophysiology and pharmacotherapy of bipolar disorder: current status. Clin Neurosci Res 2004;4:201-213.

94 Zhou R, Gray NA, Yuan P, Li X, Chen J, Chen G, Damschroder-Williams P, Du J, Zhang L, Manji HK: The anti-apoptotic, glucocorticoid receptor cochaperone protein BAG-1 is a long-term target for the actions of mood stabilizers. J Neurosci 2005;25:4493-4502.
\$5 Moore GJ, Bebchuk JM, Hasanat K, Chen G, Seraji-Bozorgzad N, Wilds IB, Faulk MW, Koch S, Glitz DA, Jolkovsky L, Manji HK: Lithium increases $\mathrm{N}$-acetyl-aspartate in the human brain: in vivo evidence in support of bcl-2's neurotrophic effects? Biol Psychiatry 2000;48:1-8.

96 Phillips ML, Travis MJ, Fagiolini A, Kupfer $\mathrm{D}$ : Medication effects in neuroimaging studies of bipolar disorder. Am J Psychiatry 2008;165:313-320.

97 Drevets WC, Price JL, Simpson JR Jr, Todd RD, Reich T, Vannier M, Raichle ME: Subgenual prefrontal cortex abnormalities in mood disorders. Nature 1997;386:824827.

$\$ 98$ Bowley MP, Drevets WC, Ongur D, Price JL: Low glial numbers in the amygdala in major depressive disorder. Biol Psychiatry 2002;52:404-412.

$\$ 99$ Moore GJ, Cortese BM, Glitz DA, ZajacBenitez C, Quiroz JA, Uhde TW, Drevets WC, Manji HK: A longitudinal study of the effects of lithium treatment on prefrontal and subgenual prefrontal gray matter volume in treatment-responsive bipolar disorder patients. J Clin Psychiatry 2009;70:699705.

100 Sassi RB, Brambilla P, Hatch JP, Nicoletti MA, Mallinger AG, Frank E, Kupfer DJ, Keshavan MS, Soares JC: Reduced left anterior cingulate volumes in untreated bipolar patients. Biol Psychiatry 2004;56:467-475.

101 Sassi RB, Nicoletti M, Brambilla P, Mallinger AG, Frank E, Kupfer DJ, Keshavan MS, Soares JC: Increased gray matter volume in lithium-treated bipolar disorder patients. Neurosci Lett 2002;329:243-245.
102 Bearden CE, Thompson PM, Dalwani M, Hayashi KM, Lee AD, Nicoletti M, Trakhtenbroit M, Glahn DC, Brambilla P, Sassi RB, Mallinger AG, Frank E, Kupfer DJ, Soares JC: Greater cortical gray matter density in lithium-treated patients with bipolar disorder. Biol Psychiatry 2007;62:7-16.

103 Bearden CE, Thompson PM, Dutton RA, Frey BN, Peluso MA, Nicoletti M, Dierschke N, Hayashi KM, Klunder AD, Glahn DC, Brambilla P, Sassi RB, Mallinger AG, Soares JC: Three-dimensional mapping of hippocampal anatomy in unmedicated and lithium-treated patients with bipolar disorder. Neuropsychopharmacology 2008;33: 1229-1238.

104 Yucel K, McKinnon MC, Taylor VH, Macdonald K, Alda M, Young LT, MacQueen GM: Bilateral hippocampal volume increases after long-term lithium treatment in patients with bipolar disorder: a longitudinal MRI study. Psychopharmacology (Berl) 2007;195:357-367.

105 Yucel K, Taylor VH, McKinnon MC, Macdonald K, Alda M, Young LT, MacQueen GM: Bilateral hippocampal volume increase in patients with bipolar disorder and short-term lithium treatment. Neuropsychopharmacology 2008;33:361-367.

106 Machado-Vieira R, Manji HK, Zarate CA Jr: The role of lithium in the treatment of bipolar disorder: convergent evidence for neurotrophic effects as a unifying hypothesis, Bipolar Disord 2009;11(suppl 2):92109.

107 Fornai F, Longone P, Ferrucci M, Lenzi P, Isidoro C, Ruggieri S, Paparelli A: Autophagy and amyotrophic lateral sclerosis: the multiple roles of lithium. Autophagy 2008; 4:527-530. 